\title{
Randomized clinical trial comparing inguinal hernia repair with Lichtenstein technique using non-absorbable or partially absorbable mesh. Preliminary report
}

\author{
Konrad Pielaciński ${ }^{1}$, Andrzej B. Szczepanik ${ }^{1}$, Andrzej Misiak ${ }^{1}$,Tadeusz Wróblewski ${ }^{2}$ \\ 1Department of General and Haematological Surgery, Institute of Haematology and Transfusion Medicine, Warsaw, Poland \\ 2Department of General, Transplant and Liver Surgery, Warsaw Medical University, Poland
}

Videosurgery and Other Miniinvasive Techniques 2011; 6 (4): 190-206 DOI: 10.5114/wiitm.2011.26253

\begin{abstract}
Introduction: The Lichtenstein technique is currently considered the "gold standard" of open, anterior inguinal hernia repair. It is not free, however, of adverse effects, which may be caused by the implemented synthetic material.

Aim: Determination the influence of the mesh employed on treatment results including immediate complications, return to everyday activities, chronic pain occurrence and hernia recurrence.

Material and methods: Tension-free hernia repair using the Lichtenstein technique was performed in all the 59 patients randomized to trial groups. Group $P$ with heavyweight polypropylene mesh contained 34 patients; group $V$ with lightweight, partially absorbable mesh (polypropylene/polyglactin 910) consisted of 25 people. Controlled, scheduled follow-up appointments took place after the $7^{\text {th }}$ day and the $3^{\text {rd }}$ and $6^{\text {th }}$ month. Patients were clinically assessed and pain intensity was determined on an analogue-visual scale.

Results: No statistically significant influence of the type of mesh on the risk of early complications, severe pain intensity, the length of hospital stay, time of recovery, or patients' satisfaction with treatment was observed. After 6 months also no statistically significant differences were observed between groups with regard to recurrence rate ( $P 3.4 \%$ vs. $V 4.0 \%$ ), chronic pain (P 5.9\% vs. V 4.0\%) and ailments such as "foreign body presence" (V vs. P, OR $=0.30,95 \% \mathrm{CI}$ $0.077-1.219, p=0.093$ ) incidence, although their probability was $70 \%$ lower for $V$ mesh.

Conclusions: The preliminary results confirm the effectiveness of the Lichtenstein technique for hernia repair with both types of meshes. It appears that use of a partially absorbable mesh is connected with lower risk of postoperative complications, but the final results require multicentre trials in a larger series of patients.
\end{abstract}

Key words: inguinal hernia, Lichtenstein technique, non-absorbable and partially absorbable mesh.

\section{Introduction}

Inguinal hernias are the most common primary, true hernias in people and their incidence rate is estimated at $27 \%$ in men and $3 \%$ in women during lifetime [1]. Considering such frequent occurrence, inguinal hernia repairs are the most common procedures performed globally (around $20 \mathrm{~m}$ a year) and in
Poland (around 40-60 000 a year) [1-3]. At present, surgical methods of inguinal hernia repair can be divided into tension (traditional, pure tissue) repairs, Bassini's technique with numerous modifications being one of them, and tension-free with the use of synthetic materials (meshes) as prosthesis for fascia loss. Those, in turn, are divided with regard to mesh placement site in relation to the transverse fascia 
into anterior, e.g. Lichtenstein method, and posterior with the mesh placed behind transverse fascia utilizing Nyphus, Stoppa, Rives and Read procedure, open technique or video-assisted technique [2, 4, 5]. Disadvantages of standard tissue methods such as high recurrence rate (10-20\%), long, postoperative pain sensation and recovery time $[2,6]$, made tension-free techniques, both video-assisted and open, methods of choice for inguinal hernia repair [1, 6-8]. Currently, the gold standard is that of Lichtenstein, which is employed for the majority of primary inguinal hernia repairs [1, 2]. It is so because of the minimal complications and a low recurrence rate, around $1 \%$. What is more, it is characterized by short postoperative pain sensation and fast return to basic activities of daily living $[1,2,6,7,9]$. Despite the high effectiveness in hernia recurrence prevention, tension-free repairs are not entirely free of adverse effects. Pain in the groin operated on is the most serious and most frequent postoperative ailment which worsens the results of treatment. Previous publications show that chronic pain sensation appears regardless of the surgical technique employed and is recognized to affect a considerable number of patients (around 28\%). Among those operated on, $16 \%$ report complaints of various degree, and $8 \%$ substantial impairment in quality of life as a result of chronic pain [10]. Tension on the suture line created to close the hernial ring after inguinal hernia tissue repairs is believed to be responsible for pain and chronic pain sensations [1, 2, $8,11]$. In the case of tension-free techniques, the implant, its type and location, may cause pain. The incidence of pain in patients undergoing mesh repair is lower and on average is $11 \%$, and in the case of Lichtenstein technique only $6 \%[10,12]$. Traditional, heavyweight polypropylene meshes may cause more intense afflictions than lightweight meshes, e.g. partially absorbable meshes [13-15]. Results of previous studies do not decisively confirm those observations, especially the ones which employed long-term observation of patients [16-18].

\section{Aim}

The goal of the study was to determine whether the type of mesh, heavyweight, non-absorbable vs. lightweight partially absorbable, used for inguinal hernia repair influences hernia recurrence, technical difficulties during the procedure, perioperative com- plications incidence, need for analgesics, postoperative pain intensity, recovery time and subjective opinion of patients.

\section{Material and methods}

Treatment results of 59 male patients aged from 23 years to 89 years with Lichtenstein inguinal hernia repair performed were assessed. The series was divided into two groups, group P (34 people) with a heavyweight, polypropylene mesh and group $\mathrm{V}$ (25 people) with a lightweight composite mesh (polypropylene/ polyglactin 910). Both groups are characterized in Table I. The inclusion criteria were as follows: age over 18 years, primary or recurrent (after tension techniques) inguinal hernia, no other lesions in the operated groin or scrotum. After obtaining their informed consent for the study, patients were randomized without being informed what mesh would be used during the procedure. Before transporting the patient to the OR, the groin operated on was shaved and primarily disinfected. The procedure was performed under obligatory subarachnoid anaesthesia with bacterial infection and venous thromboembolic disease prophylaxis (Cefazdin and nadroparin calcium respectively).

In the case of patients with contralateral hernia, two separate procedures were performed. Hernia which was more disturbing was operated on first, and hernia on the other side after at least a month following the first surgery. Data for the surgery were collected according to a protocol in specified stages of treatment. The hernia type was determined based on the Nyhus classification system [19]. The level of technical difficulties during mesh implementation was assessed on the basis of the length of the surgical procedure. The clinical assessment was performed in the postoperative period and during scheduled follow-up appointments on the $7^{\text {th }}$ day, in the $3^{\text {rd }}$ and $6^{\text {th }}$ month. Postoperatively, patients were advised against driving until the $7^{\text {th }}$ day and riding a bike until the $14^{\text {th }}$ day after the surgery. Heavyweight lifting (above $10 \mathrm{~kg}$ ) was allowed after 3 months. The statistical analysis of data was carried out by Pearson's $\chi^{2}$ test, Fisher's exact test, Student's $t$-test, non-parametric Mann-Whitney test, likelihood ratio test (REML estimation), logistic regression models and a Poisson regression model. The study was accepted by the Bioethical Committee at the Institute of Haematology and Transfusion Medicine in Warsaw (9/2008). 
Table I. Characteristics of patients qualified for surgical treatment with polypropylene or Vypro II mesh

\begin{tabular}{|c|c|c|c|c|}
\hline Parameter & $\begin{array}{c}\text { Patients with } \\
\text { polypropylene mesh }\end{array}$ & $\begin{array}{l}\text { Patients with } \\
\text { Vypro II mesh }\end{array}$ & Total amount & $\begin{array}{c}\text { Statistical } \\
\text { significance } p / N S\end{array}$ \\
\hline Number of patients $(n)$ & 34 & 25 & 59 & - \\
\hline Age [years]: median \pm SD, & $60 \pm 14.22$ & $57 \pm 16.36$ & $59 \pm 15.1$ & 0.439 \\
\hline range & $23-89$ & $24-82$ & $23-89$ & \\
\hline Men & $32(96 \%)$ & $23(92 \%)$ & 55 (93\%) & 0.749 \\
\hline Women & $2(6 \%)$ & $2(8 \%)$ & $4(7 \%)$ & NS \\
\hline \multicolumn{5}{|l|}{ Type of hernia (Nyhus classification) } \\
\hline । & $7(21 \%)$ & $7(28 \%)$ & $14(24 \%)$ & NS \\
\hline$\|$ & $16(47 \%)$ & $6(24 \%)$ & $22(37 \%)$ & NS \\
\hline III & $10(29 \%)$ & $10(40 \%)$ & $20(34 \%)$ & NS \\
\hline IV & $1(3 \%)$ & $2(8 \%)$ & $3(5 \%)$ & 0.309 \\
\hline Left side hernia & $11(32 \%)$ & $15(60 \%)$ & $26(44 \%)$ & NS \\
\hline Right side hernia & $23(68 \%)$ & $10(40 \%)$ & $33(55 \%)$ & 0.013 \\
\hline Bilateral hernia & $5(15 \%)$ & $6(24 \%)$ & $11(19 \%)$ & 0.365 \\
\hline \multicolumn{5}{|l|}{ ASA surgical risk assessment } \\
\hline । & $14(41 \%)$ & $10(40 \%)$ & $24(41 \%)$ & NS \\
\hline ॥ & 15 (44\%) & $8(32 \%)$ & $23(39 \%)$ & NS \\
\hline III & $5(15 \%)$ & $7(28 \%)$ & $12(20 \%)$ & 0.407 \\
\hline \multicolumn{5}{|l|}{ BMI $\left[\mathrm{kg} / \mathrm{m}^{2}\right]$} \\
\hline \multicolumn{5}{|l|}{ Proper body mass } \\
\hline $18.5 \leq \mathrm{BMI} \leq 24.9$ & $18(53 \%)$ & $14(56 \%)$ & $32(54 \%)$ & NS \\
\hline \multicolumn{5}{|l|}{ Excess weight $[\mathrm{kg}]$} \\
\hline $25 \leq \mathrm{BMI} \leq 29.9$ & $11(32 \%)$ & $7(28 \%)$ & $18(31 \%)$ & NS \\
\hline \multicolumn{5}{|l|}{ Obesity $\left[\mathrm{kg} / \mathrm{m}^{2}\right]$} \\
\hline $\mathrm{BMI} \geq 30$ & $5(15 \%)$ & $4(16 \%)$ & $9(15 \%)$ & 0.937 \\
\hline Hernia in family history & $12(35 \%)$ & $12(48 \%)$ & $24(41 \%)$ & 0.326 \\
\hline Strangulation & $23(68 \%)$ & $13(52 \%)$ & $36(61 \%)$ & 0.223 \\
\hline Hernia duration [weeks], median (range) & $32(1-2400)$ & $96(2-960)$ & $96(1-2400)$ & 0.107 \\
\hline Smoking & $8(24 \%)$ & $11(44 \%)$ & $19(32 \%)$ & 0.096 \\
\hline Other concurrent hernias & $9(26 \%)$ & $8(32 \%)$ & $17(29 \%)$ & 0.643 \\
\hline Professional activity, physical & $15(44 \%)$ & $12(48 \%)$ & $27(46 \%)$ & NS \\
\hline Headwork & $1(3 \%)$ & $2(8 \%)$ & $3(5 \%)$ & 0.881 \\
\hline Pension & $16(47 \%)$ & $10(40 \%)$ & 26 (44\%) & NS \\
\hline
\end{tabular}


Table I. Cont.

\begin{tabular}{|lcccc|}
\hline Parameter & $\begin{array}{c}\text { Patients with } \\
\text { polypropylene mesh }\end{array}$ & $\begin{array}{c}\text { Patients with } \\
\text { Vypro II mesh }\end{array}$ & Total amount & $\begin{array}{c}\text { Statistical } \\
\text { significance } p / \text { ns }\end{array}$ \\
\hline Pension (health reasons) & $2(6 \%)$ & $1(4 \%)$ & $3(5 \%)$ & NS \\
\hline Sports & $9(26 \%)$ & $5(20 \%)$ & $14(24 \%)$ & 0.758 \\
\hline Previous surgery & $16(47 \%)$ & $16(64 \%)$ & $32(54 \%)$ & 0.197 \\
\hline Concurrent diseases & $18(53 \%)$ & $14(56 \%)$ & $32(54 \%)$ & 0.816 \\
\hline Medicines used & $14(42 \%)$ & $10(40 \%)$ & $24(41 \%)$ & 0.853 \\
\hline Surgeon (operator) & & & & $32(54 \%)$ \\
\hline 1 & $14(41 \%)$ & $18(72 \%)$ & $14(24 \%)$ & 0.061 \\
\hline 2 & $10(29 \%)$ & $4(16 \%)$ & $13(22 \%)$ & \\
\hline Others & $10(29 \%)$ & $3(12 \%)$ & & \\
\hline
\end{tabular}

NS - non statistical

Features of the meshes used:

1) commonly used, propylene, non-absorbable meshes sized $8 \mathrm{~cm} \times 15 \mathrm{~cm}$,

2) a mesh with pore size around $1 \mathrm{~mm}$, weighing around $100 \mathrm{~g} / \mathrm{m}^{2}$, made of non-absorbable polypropylene filaments,

3) partially absorbable mesh, so-called lightweight mesh, sized $6 \mathrm{~cm} \times 11 \mathrm{~cm}$, with 3-4 mm pores and initial weight of $80 \mathrm{~g} / \mathrm{m}^{2}$ consisting of nonabsorbable polypropylene filaments $\left(35 \mathrm{~g} / \mathrm{m}^{2}\right)$ and polyglactin filaments absorbed by hydrolysis in around 6 weeks $\left(45 \mathrm{~g} / \mathrm{m}^{2}\right)$.

\section{Operative procedure}

In order to standardize dealing with the sac and mesh placement in Lichtenstein technique the following details were modified. Primarily, spermatic cord and round ligament of the uterus were fully mobilized. However, the ligament was not cut. The inguinal hernia sac was inverted and folded with a non-absorbable suture in order to level the posterior wall of the inguinal canal. The oblique inguinal hernial sac was dissected from the spermatic cord up to the preperitoneal fat tissue, then inverted (hernia type 1 with normal internal ring, Nyphus classification) or excised (hernia type 2 with dilated internal ring, Nyphus classification). The scrotal inguinal hernia sac was cut in the middle of the inguinal canal. Its proximal stump was closed and pulled back in a sim- ilar manner as described above. The distal portion of the incised sac was excised carefully with the appropriate haemostasis.

\section{Way of mesh placement and fixation}

The posterior wall of the inguinal canal was covered with an appropriately tailored (regarding size and shape) mesh. The mesh was cut up from lateral to medial so that its bottom portion (in relation to the spermatic cord) constituted $1 / 3$ of the mesh, and its upper part $2 / 3$. The mesh must be wide enough to easily underlie the upper aponeurosis of the external oblique muscle and its inferior edge should extend to or cover the inguinal ligament. The inferomedial corner of the mesh was fixed to soft tissue covering the pubic tubercle (without piercing it) and was done with the continuous suture technique (polypropylene, non-absorbable suture). It is extremely important that the mesh covers the pubic tubercle with a $2-3 \mathrm{~cm}$ margin. The inferior rim was sewn to Poupart's ligament with the loose continuous suture, and the upper edge was sewn in a similar manner under the aponeurosis of the external oblique muscle.

The rims of the cut mesh were laterally crossed away from the spermatic cord and ligated with one or two sutures in order to ensure their good fit around the cord. After the mesh placement, a vacuum drain (Redon) was inserted through a separate, percutaneous incision, and the aponeurosis of the 
external oblique muscle was closed with a continuous suture of absorbable type. The wound was typically closed - subcutaneous tissue with absorbable sutures, and the skin with a single suture. Application of bandage finished the procedure. In the other aspects the procedure was in accordance with the technique described by the authors [2]. Ketoprofen was used as the first-line analgesic, and metamizole sodium as the second-line analgesic in case of insufficient pain control or allergy to the drug of the first line. After $24 \mathrm{~h}$ patients were allowed to walk. They were released home on the $1^{\text {st }}$ or $2^{\text {nd }}$ postoperative day, which depended on the patient's general condition. Having already been released, the patients determined their pain level on a visual analogue scale (VAS) and verbal scale from the $1^{\text {st }}$ to the $7^{\text {th }}$ postoperative day and noted down the amounts of the analgesic used.

\section{Statistical methods}

The characteristics of the studied groups are presented in Table II according to the type of mesh implanted. The observed variables were compared by Pearson's $\chi^{2}$ test or Fisher's exact test in the case of categorical variables or Student's $t$-test (non-parametric Mann-Whitney test alternatively) for continuous variables. Early and intraoperative complications were analysed by logistic regression models. The initial model assessing the risk of early complications included: mesh type, hernia type, body mass determined by body mass index (BMI), functional status according to ASA scale, hernia duration (categorized by median of 96 weeks), interactions between the mesh and hernia type, previous surgery (yes/no), operator, date (continuous variable with isolated increase, every 2 months) and bilateral hernia indicator. This is a standard set of variables used in multifactor models in the present study. The length of the procedure, day of recovery, the number of days in hospital, the amount of drainage from the wound on the $1^{\text {st }}$ and $2^{\text {nd }}$ day and the total dosage of analgesic used in 7 days were analysed by the regression mod- el with the same set of variables as in the initial model. The additional single-factor analysis was performed for the duration of the procedure and date of return to everyday activities. Changeability in the amount of the analgesic used over time and values on the pain scale were analysed by a mixed model explaining the level of the given parameter by means of fixed and random effects models which took into account patients' individual diversity. The sensitivity of fixed effects and the correlation matrix type for specific points in time were tested by the likelihood ratio test (REML estimation). The sensitivity of random effects was tested by mixed $\chi^{2}$ distribution with different degrees of freedom. Seven points in time for the pain scale and 8 points in time for analgesic were included in the analysis. The compatibility of verbal pain and VAS scales was assessed by means of kappa coefficient with the use of a scaler included in Table I. Pain scales after 3 and 6 months were analysed separately by Poisson regression models with a standard set of explanatory variables extended by age and sex. The risk of afflictions in the $3^{\text {rd }}$ and $6^{\text {th }}$ month was tested by logistic models with the same set of explanatory variables. The impact of those variables on the degree ailments impeded everyday activities was analysed by Poisson models. The analysis of medicine dosage, postoperative pain intensity, return to everyday activities, patient's subjective assessment, cases of pain and afflictions was performed in a group reduced to 41 patients due to exclusion of some patients because of early complications, concurrent diseases exacerbation and the lack of data resulting from failing scheduled followup appointments. The influence of the following variables on cases of exclusion from further dialysis were tested by the logistic regression model: type of mesh, type of hernia, body mass, ASA assessment, duration of hernia, hernia and mesh type interaction, previous surgery (yes/no), operator, date of the procedure, bilateral hernia indicator. The influence of the above factors on patients' opinion on the surgical result and treatment was also examined. Third and sixth month

Table II. Method of converting pain intensity assessment between VAS and VRS scale

\begin{tabular}{|lcccccc|}
\hline VAS & 0 & $0.1-2$ & $2.1-4$ & $4.1-6$ & $6.1-8$ & $8.1-10$ \\
\hline Coded verbal scale & 0 & 1 & 2 & 3 & 5 \\
\hline Verbal scale & No pain & Little pain & Mild pain & Moderate pain & Severe pain & Worst pain possible \\
\hline
\end{tabular}


ailments were also included in the set of explanatory variables. For binary doctor's assessment a logistic model was used, while for subjective patient's assessment a Poisson regression model was employed. In tables for mixed models, estimated fixed effects together with $p$ values were placed. For normal regression models the tables include, apart from the ratio estimation for the particular variable, $p$-value and a 95\% confidence interval for the ratio. For Poisson regression models the tables include, besides incidence rate ratio (IRR) estimation for the particular variable, $p$-value and a $95 \%$ confidence interval for IRR. For logistic regression models the tables include, besides $p$-value, odds ratio (OR) and $95 \%$ confidence interval for OR. In all the tests the statistical significance was assumed at 0.05 .

\section{Results}

The characteristics of the studied groups are presented in Table II according to the type of mesh implanted. Eigthteen patients altogether were excluded from both groups, 10 from the group with the polypropylene mesh (29\%), and 8 from the group with Vypro II mesh (32\%). The difference was not statistically significant $(p=0.831)$. In 14 of the excluded patients symptoms of strangulated hernia were observed (78\%). Causes of patients' exclusion from both groups are presented in Table III. After that 41 patients were further analysed, 24 with a polypropylene mesh $(\mathrm{P})$ and 17 with Vypro II (V).

\section{Early complications}

Strangulation was the only factor significantly influencing the likelihood of patients' exclusion due to early complications, which when it occurred was increased by more than 6 times $(p=0.027)$. The incidence of early complications decreased with the duration of the study. The later the procedure was performed since the beginning of the study, the smaller became the risk, on average by $35 \%$ for every 2 months of the study. Overweight or obese patients presented 5 times higher risk of early complications in comparison to non-obese ones. The risk of early complications was $73 \%$ in patients having undergone different types of treatment prior to hernia repair in comparison to patients with no previous treatment. The statistically significant factors influencing early complications occurrence are presented in Table IV.

Ninety-eight percent higher risk of anatomical damage occurred in patients with hernia type II or III than in patients with hernia type I $(p=0.021)$.

\section{Duration of the procedure}

The relationship between the duration of the procedure and different factors analysed is presented in Table V. In the single-factor analysis the date of the procedure, type of hernia and operator appeared to be significant. In the multi-factor analysis the significance of the date of the procedure, operator, type of mesh, ASA assessment and duration of hernia were confirmed. The study was divided into two 2-month

Table III. Causes of 18 patients' exclusion

\begin{tabular}{|lccc|}
\hline Causes of exclusion & $N=59, n(\%)^{*}$ & $\begin{array}{c}\text { Patients with } \\
\text { polypropylene mesh }\end{array}$ & $\begin{array}{c}\text { Patients with } \\
\text { Vypro II mesh }\end{array}$ \\
\hline Hernia recurrence & $2(3.4 \%)$ & $1(3 \%)$ & $1(4 \%)$ \\
\hline Immediate local complications (hematoma, serum tumour) & $6(10.2 \%)$ & $2(6 \%)$ & $4(16 \%)$ \\
\hline Cut deferent duct & $1(1.7 \%)$ & 0 & $1(4 \%)$ \\
\hline Cut iliohypogastric nerve & $2(3.4 \%)$ & $1(3 \%)$ & $1(4 \%)$ \\
\hline Purulent postoperative wound & $1(1.7 \%)$ & $1(3 \%)$ & 0 \\
\hline Bathyhypoesthesia & $3(5.1 \%)$ & $1(3 \%)$ & $2(8 \%)$ \\
\hline Other complications & $3(5.1 \%)$ & $1(3 \%)$ & $2(8 \%)$ \\
\hline Concurrent diseases exacerbation & $3(5.1 \%)$ & $2(6 \%)$ & $1(4 \%)$ \\
\hline Failing scheduled follow-up appointments & $2(3.4 \%)$ & $2(6 \%)$ & 0 \\
\hline
\end{tabular}

*Percentage does not sum up to 1 due to more than 1 circumstance in case of 1 person 
Table IV. Results for logistic regression model for early complications risk

\begin{tabular}{|lcccc|}
\hline Variable & OR & \multicolumn{2}{c|}{$95 \%$ Cl (OR) } & Value of $p$ \\
\hline BMI (2,3 vs. 1) & 4.916 & 1.271 & 19.009 & 0.021 \\
\hline Date & 0.655 & 0.436 & 0.985 & 0.042 \\
\hline Previous surgery & 0.264 & 0.073 & 0.959 & 0.043 \\
\hline
\end{tabular}

intervals. The procedure duration decreased by 2.3 min on average for each interval. Duration of the procedure performed by the same operator decreased on average by 11 min when the type of mesh, duration of hernia, ASA condition and 2-month period remained the same. ASA $=3$ prolonged the surgery by 13 min in case of the same operator, type of mesh and a respective 2-month period. $V$ type mesh shortened the median duration of the procedure by $7.5 \mathrm{~min}$ given the same operator and ASA condition. In the case of patients operated on later than 96 weeks from the hernia occurrence, the duration of the procedure was on average 7 min longer when the operator, ASA condition, and type of mesh remained the same. The above-mentioned cases applied to 2-month intervals in which the surgery was performed.

\section{The amount of wound drainage}

The final model for the amount of drainage on the $1^{\text {st }}$ and $2^{\text {nd }}$ postoperative day included only the operator, but this variable was statistically significant only for the $2^{\text {nd }}$ day. When the procedure had not been performed by operator 1 or 2 , the amount of drainage was on average increased by $11.7 \mathrm{ml}(p<0.05)$.

\section{The length of hospital stay}

It was observed that when the procedure was performed by operator 2, the length of hospital stay was shortened by 0.5 day in comparison to patients operated on by operator $1(p=0.028)$. When it was not performed by operator 1 or 2 the length of hospital stay was prolonged by 0.5 day. The relationship between the mesh and hernia type did not reach statistical significance at the level of 0.05. ASA class III accounted for prolonged hospital stay (0.6 days longer, $p=0.022$ ). Postoperative pain intensity was assessed by means of a VAS scale. The standard model (for this study), extended by such variables as time trend, quadratic trend and interactions between them, was used to assess pain intensity. In the final model time trend and the relationship between time trend and variable concerning cases of hernia in family history were included as statistically significant. The influence of other variables such as the type of mesh and hernia, body mass and others turned out to be statistically insignificant. In Figure 1, median values for pain intensity from 7 postoperative days measured on the VAS scale are presented according to the type of mesh, type of hernia and both variables together. Ratio negative value for constant trend effect in the model reveals general pain intensity decrease over time, on average 0.13 point on the VAS scale. The covariance matrix between the particular time points was left in the free-form structure. The observed estimation values show the most significant differentiation between patients at the $1^{\text {st }}$ and last time point (day). The smallest differentiation was observed at the $5^{\text {th }}$ time point. The model contained only a statistically significant random constant term showing strong individual differentiation (on the $1^{\text {st }}$ day after the surgery) on the pain scale among patients.

\section{The comparison of pain assessment on VAS and VRS scales}

The consistency between VAS and VRS scales assessments amounted to $50-80 \%$ at respective time points; each time it exceeded the level of statistical significance.

\section{Analgesic requirements}

Analgesic consumption up to 8 days after surgery in relation to factors analysed is presented in Table $\mathrm{VI}$, and median daily dosage by a) the type of mesh, b) type of hernia and mesh relationship are presented in Figure 2. Hernia type II decreased the total amount of the medicine used by $368 \mathrm{mg}$. Total, median amount of the medicine was increased by $307 \mathrm{mg}$ when $V$ type mesh was used (the comparison in all 
Table V. Results for regression model for the length of the procedure: single factor and multifactor

\begin{tabular}{|c|c|c|c|c|}
\hline Variable & Estimate (B) & \multicolumn{2}{|c|}{$95 \% \mathrm{Cl}(\mathrm{B})$} & Value of $p$ \\
\hline \multicolumn{5}{|l|}{ Single factor } \\
\hline Date of procedure & -2.670 & -4.757 & -0.583 & 0.013 \\
\hline Type of mesh (V vs. P) & -5.494 & -12.913 & 1.924 & 0.144 \\
\hline Bilateral & 2.5 & -7.069 & 12.069 & 0.603 \\
\hline \multicolumn{5}{|l|}{ Type of hernia } \\
\hline 2 vs. 1 & 11.785 & 2.477 & 21.094 & 0.014 \\
\hline 3 vs. 1 & 5.785 & -3.702 & 15.273 & 0.227 \\
\hline 4 vs. 1 & 17.619 & 0.296 & 34.941 & 0.046 \\
\hline \multicolumn{5}{|l|}{ Type of mesh/type of hernia } \\
\hline$(\mathrm{V}, 2)$ vs. $(\mathrm{V}, 1)$ or $\mathrm{P}$ & 0.565 & -19.156 & 20.287 & 0.954 \\
\hline$(\mathrm{V}, 3)$ vs. $(\mathrm{V}, 1)$ or $\mathrm{P}$ & -2.142 & -21.297 & 17.012 & 0.823 \\
\hline$(\mathrm{V}, 4)$ vs. $(\mathrm{V}, 1)$ or $\mathrm{P}$ & -22.142 & -58.871 & 14.585 & 0.232 \\
\hline \multicolumn{5}{|l|}{ Surgeon (2 vs. others) } \\
\hline 2 vs. 1 & -10.223 & -19.089 & -1.357 & 0.025 \\
\hline Others vs. 1 & -2.475 & -11.576 & 6.624 & 0.588 \\
\hline Previous surgery (Yes vs. No) & -2.725 & -10.189 & 4.738 & 0.468 \\
\hline \multicolumn{5}{|l|}{ ASA } \\
\hline |l vs. I & 2.137 & -5.634 & 9.909 & 0.584 \\
\hline III vs. I & 14.583 & 5.166 & 24.000 & \\
\hline \multicolumn{5}{|l|}{ BMI } \\
\hline 2 vs. 1 & -0.868 & -9.372 & 7.636 & 0.839 \\
\hline 3 vs. 1 & 2.743 & -8.147 & 13.633 & 0.616 \\
\hline Hernia duration ( $\geq 96$ weeks vs. $<96$ weeks) & 4.816 & -2.546 & 12.179 & 0.196 \\
\hline \multicolumn{5}{|l|}{ Multifactor } \\
\hline Constant term & 58.435 & 48.921 & 67.950 & $<0.001$ \\
\hline Date of procedure & -2.296 & -4.154 & -0.438 & 0.016 \\
\hline Type of mesh (V vs. P) & -7.521 & -13.729 & -1.312 & 0.019 \\
\hline Operator (2 vs. others) & -11.398 & -18.419 & -4.377 & 0.002 \\
\hline ASA (III vs. other) & 13.200 & 5.556 & 20.844 & 0.001 \\
\hline Hernia duration ( $\geq 96$ weeks vs. $<96$ weeks) & 6.689 & 0.523 & 12.856 & 0.034 \\
\hline
\end{tabular}

the patients $V$ vs. P with the fixed levels of other model variables). The relationship between the type of mesh and hernia is as follows. $V$ type mesh and hernia type 4 decreased the total amount of analgesic by $420 \mathrm{mg}$ in relation to patients with $V$ mesh and hernia type 1 and 2 and all the patients with $P$ 
A

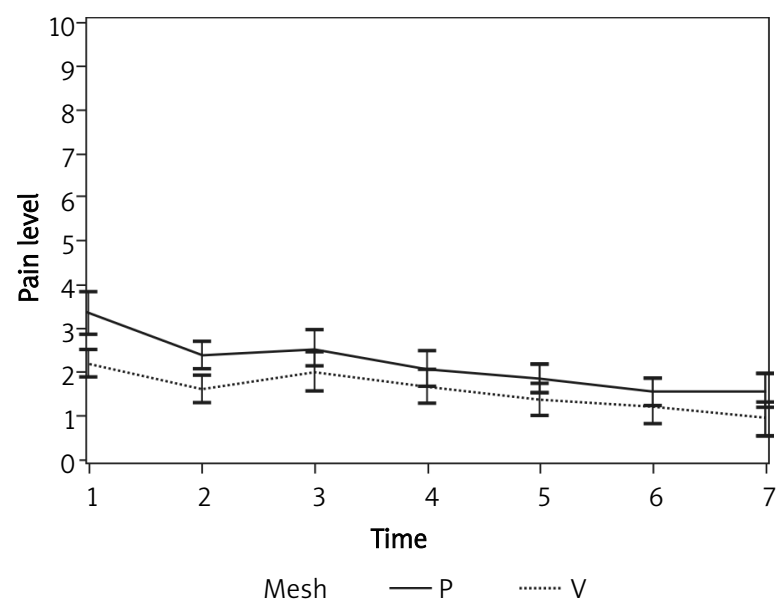

C

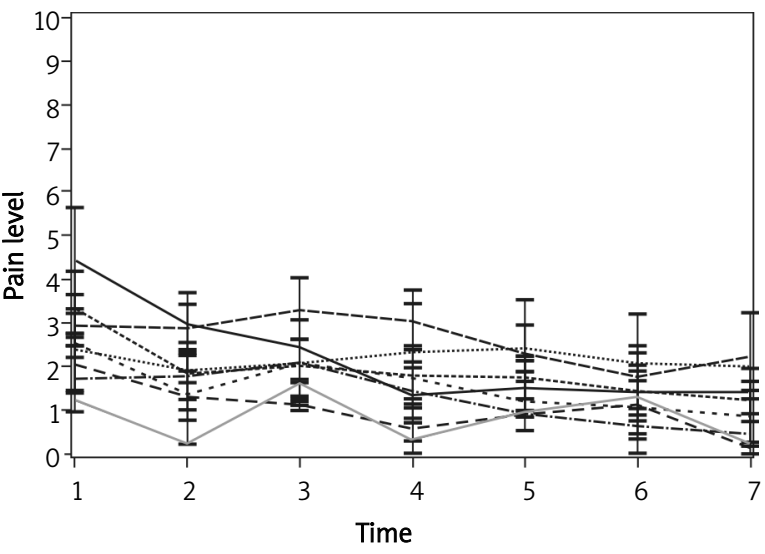

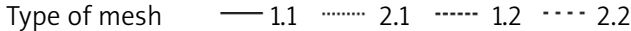

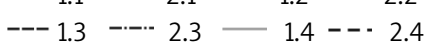

mesh. $\vee$ type mesh and hernia type 3 decreased the total amount of the analgesic by $518 \mathrm{mg}$ in relation to patients with $V$ type mesh and hernia type 1 and 2 and all the patients with $\mathrm{P}$ mesh. Finally, the above described effects caused the following differences between the amounts of analgesics patients used. Patients with $V$ type mesh and hernia type 1 and 2 presented increased requirements. The amount of analgesic used by them was higher by $307 \mathrm{mg}$ than in the case of all the patients with mesh type $\mathrm{P}$, higher by $96 \mathrm{mg}$ than patients with $\mathrm{V}$ type mesh and hernia type 3 and higher by $113 \mathrm{mg}$ than patients with $\mathrm{V}$ type mesh and hernia type 4 . ASA $=3$ did not reach statistical significance. When the surgery was performed by an operator other than 1 or 2, the total amount of the analgesic used was increased by
B

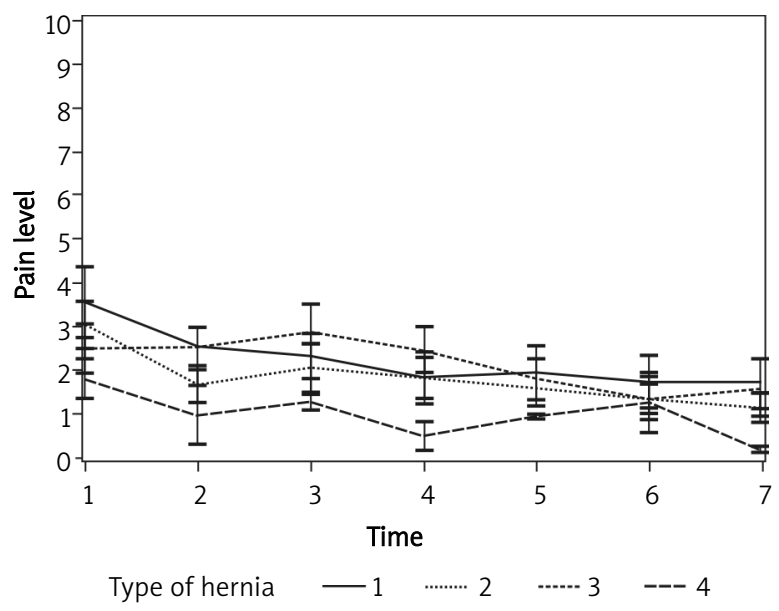

Figure 1. Median values of VAS scores from $1^{\text {st }}$ to 7 th postoperative day with regards to the A) type of mesh, B) type of hernia, C) interactions between kind of mesh and type together with $95 \%$ levels of confidence

$537 \mathrm{mg}$. The standard model (for this study), extended by such variables as time trend, quadratic trend and the relationship between both of them, was employed to assess the changes in the daily requirement for the analgesic. The type of mesh and the relationship between the type of hernia and mesh were included in the final model for the analgesic used. Furthermore, the constant effect of the linear and quadratic trend appeared to be significant. Only patients with hernia type 1 differed significantly from others in terms of changes in the amount of medicine used over time. Median dose of an analgesic taken by patients with hernia type 1 was $57 \mathrm{ml}$ greater than in other patients $(p=0.017)$. The influence of hernia type 1 was modified by the type of mesh, though. Patients with mesh type P implanted 
every day used less analgesic (around $60 \mathrm{ml}$ ) than all other patients $(p=0.014)$. In Figure 2 there are median values of medicine up to the $8^{\text {th }}$ postoperative day divided by mesh type, hernia type and both variables together. Figure 2 shows that the lowest doses of medicine were taken by patients with her-

Table Vl. Results for regression model for the total amount of the analgesic used over the period of 8 days

\begin{tabular}{|lcccc|}
\hline Variable & Estimate (B) & \multicolumn{2}{c}{$95 \% \mathrm{Cl}(\mathrm{B})$} & Value of $p$ \\
\hline Constant term & 537.521 & 418.726 & 656.316 & $<0.001$ \\
\hline Type of mesh (V vs. P) & 307.349 & 117.935 & 496.763 & 0.002 \\
\hline Type of hernia (2 vs. other) & -368.629 & -545.277 & -191.199 & $<0.001$ \\
\hline Type of mesh/type of hernia (V,4) & -419.870 & -795.541 & -44.199 & 0.030 \\
\hline Type of mesh/type of hernia (V,3) & -518.439 & -789.914 & -246.966 & $<0.001$ \\
\hline Operator (others vs. 1,2) & 291.683 & 70.382 & 512.984 & 0.011 \\
\hline ASA (III vs. other) & -182.152 & -388.693 & 24.388 & 0.082 \\
\hline
\end{tabular}

A

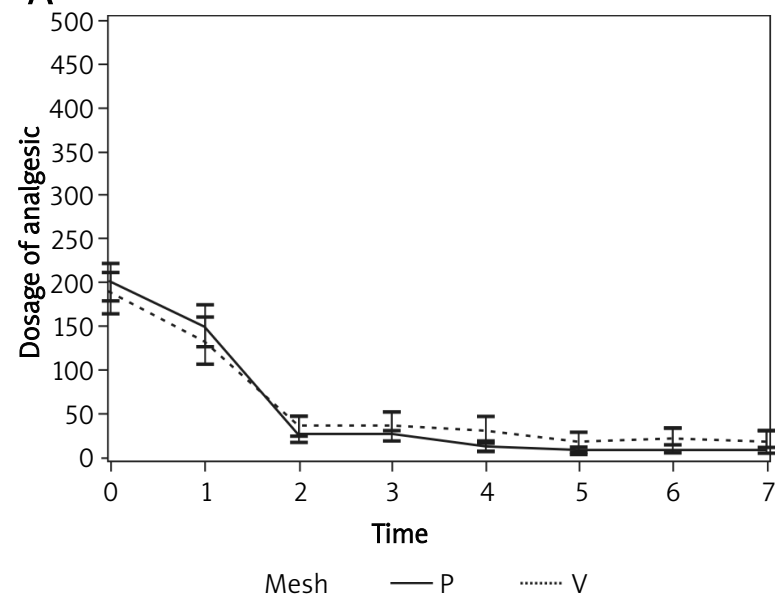

C

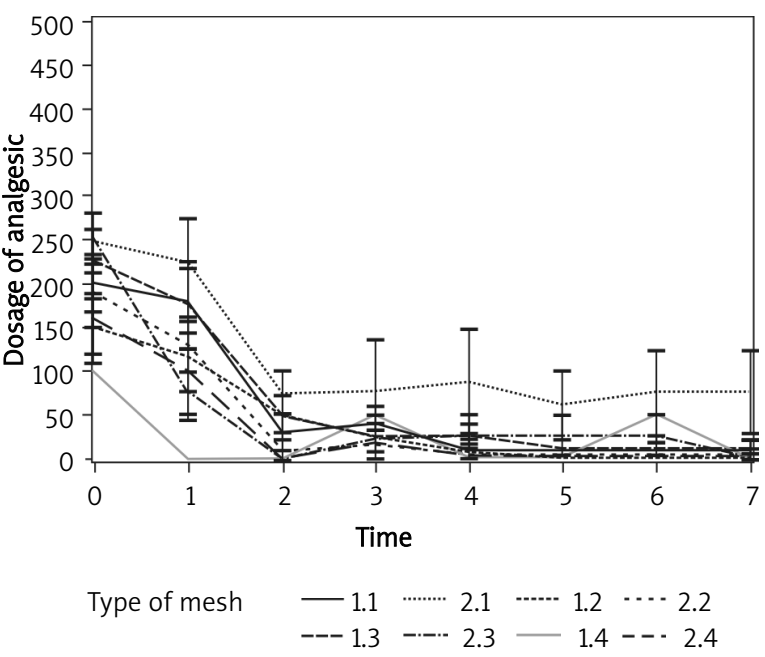

B

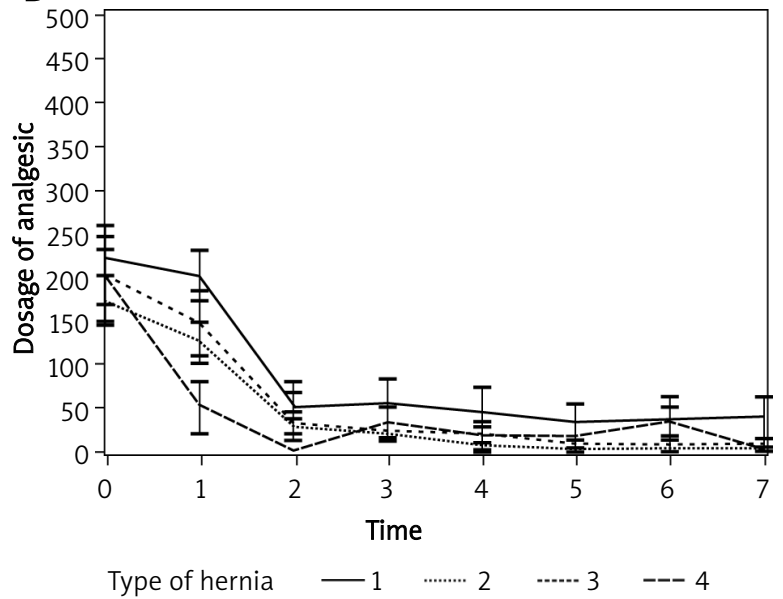

Figure 2. Median, daily doses of an analgesic, in milligrams, used by patients from the day of surgery to the 7 th day with regards to the A) type of mesh employed, B) type of hernia, C) interactions between kind of mesh and type of hernia (type of mesh $1=P, 2=V$, type of hernia) together with $95 \%$ levels of confidence 
nia type 1 and mesh type $P$, while the highest doses were taken by patients with the same type of hernia, but with a $V$ mesh.

The negative value of ratio for constant trend effect (for median amount of an analgesic used) in the model reveals a general drop in the amount of analgesic used over time by $75 \mathrm{ml}$ per day. The covariance matrix between respective days in the model was simplified from a free-form structure to ARH (1) (heterogeneous AR [1]). This form assumes different variances for every postoperative day and $1^{\text {st }}$ degree autoregressive correlation. The obtained estimations show the highest differentiation of the analgesic dosage depending on the patient on the $2^{\text {nd }}$ and $3^{\text {rd }}$ postoperative day. The lowest differentiation occurred on the $6^{\text {th }}$ postoperative day. The model contained a statistically significant random constant term showing high individual differentiation among patients of the base amounts (on the $1^{\text {st }}$ postoperative day) of the medicines taken. In addition, the model contained a linear and quadratic trend random effect. The matrix between random effects (individual amounts of the medicine taken) assumed free form. Estimated parameters for the matrix showed a negative correlation between base values and the following linear trend, so patients with a high base amount of an analgesic (with a high amount of the medicine taken on the $1^{\text {st }}$ postoperative day) experienced a faster drop in the amount of the taken drug.

\section{Return to normal activities of daily living}

The day patients resumed their normal activities of daily living depending on parameters tested is presented in Table VII. The recovery time of patients with bilateral hernias (they were operated upon twice, with the minimum of 1-month interval between operations, and they were treated as patients with lateral hernias with features of bilateral hernias) was shortened by 4 days. Patients classified as ASA 1 or 2 recovered on average 3.5 days earlier. The recovery time decreased with the study duration. For every 2 months, it got about 1 day shorter. Seventy cases of limitations upon recovery were observed. They were caused by a pulling sensation ( 9 cases), stinging sensation (4 cases), the presence of a foreign body, burning sensation, tightness, or itching, one case for each feeling. The limitations made body position changes (10 cases), or walking (2 cases) difficult. In other cases they appeared sporadically when different activities were performed.

\section{Changes in analgesic requirement in the postoperative period}

\section{Hernia recurrence}

In the whole group, 2 cases (3.4\%) of hernia recurrence were observed, one for each type of mesh: $\mathrm{P} 1$ (3\%), V 1 (4\%). The difference is not statistically significant.

\section{Pain and ailments in the groin operated upon in the $3^{\text {rd }}$ and $6^{\text {th }}$ month after the surgery}

After the $3^{\text {rd }}$ postoperative month, pain was observed in the groin operated upon in 5 patients altogether, $3(8.8 \%)$ with $\mathrm{P}$ mesh and 2 (8\%) with $\mathrm{V}$ mesh. After the $6^{\text {th }}$ postoperative month, pain was observed in 3 patients, 2 (5.9\%) with $\mathrm{P}$ mesh and 1 (4\%) with $\vee$ mesh. The above observed differences in the groups studied ( $P$ vs. V) are not statistically significant. Pain intensity after the $3^{\text {rd }}$ postoperative month was determined by the patients on the VRS scale as "small" to "medium". Only the patient with "medium" pain sensation took ketoprophen. After the $6^{\text {th }}$ month 3 out of 41 patients felt pain in the groin (VRS scale from 1 to 3 one case each). The patients feeling $2^{\text {nd }}$ and $3^{\text {rd }}$ degree pain after the $6^{\text {th }}$ month took ketoprophen. The patients feeling $1^{\text {st }}$ and $2^{\text {nd }}$ degree pain after the $6^{\text {th }}$ month did not feel it at all after the $3^{\text {rd }}$ month. The patient feeling $3^{\text {rd }}$ degree pain according to the VRS scale after the $6^{\text {th }}$ month felt $1^{\text {st }}$ degree pain after the $3^{\text {rd }}$ month.

The remaining 4 patients feeling pain after the $3^{\text {rd }}$ month did not feel any after the $6^{\text {th }}$ month. The scales' consistency after the $3^{\text {rd }}$ and $6^{\text {th }}$ month was at $83 \%$.

Table VIII shows the Poisson regression model for cases of pain occurring up to 3 months (A), and up to 6 months (B).

After the $3^{\text {rd }}$ month, ten times stronger pain was observed in patients operated on by a surgeon other than 1 or 2. Patients classified as ASA 3 felt pain 4 times more intense - the result was not statistically significant. After the $6^{\text {th }}$ month patients with hernia type 2 felt 9 times stronger pain than others. The influence of the operator appeared to be insignificant. Eighteen patients out of 41 suffered different ailments after the $3^{\text {rd }}$ month and 16 after the $6^{\text {th }}$ month. Fifty percent of patients suffering ailments after the $3^{\text {rd }}$ month also suffered them after the $6^{\text {th }}$ 
Table VII. Results for regression model for recovery time single factor and multifactor

\begin{tabular}{|c|c|c|c|c|}
\hline Variable & Estimate (B) & \multicolumn{2}{|c|}{$95 \% \mathrm{Cl}(\mathrm{B})$} & Value of $p$ \\
\hline \multicolumn{5}{|l|}{ Single factor } \\
\hline Date of the procedure & -1.358 & -2.206 & -0.510 & 0.002 \\
\hline Type of mesh (V vs. P) & -0.635 & -3.930 & 2.661 & 0.699 \\
\hline Bilateral & -2.503 & -6.084 & 1.078 & 0.165 \\
\hline \multicolumn{5}{|l|}{ Type of hernia } \\
\hline 2 vs. 1 & -0.298 & -4.687 & 4.090 & 0.891 \\
\hline 3 vs. 1 & -2.111 & -6.678 & 2.456 & 0.355 \\
\hline 4 vs. 1 & -1.777 & -8.800 & 5.245 & 0.611 \\
\hline \multicolumn{5}{|l|}{ Type of mesh/type of hernia } \\
\hline$(\mathrm{V}, 2)$ vs. $(\mathrm{V}, 1)$ or $\mathrm{P}$ & -8.366 & -17.305 & 0.571 & 0.066 \\
\hline$(\mathrm{V}, 3)$ vs. $(\mathrm{V}, 1)$ or $\mathrm{P}$ & -6.175 & -15.469 & 3.119 & 0.186 \\
\hline$(\mathrm{V}, 4)$ vs. $(\mathrm{V}, 1)$ or $\mathrm{P}$ & -9.2 & -23.943 & 5.543 & 0.213 \\
\hline \multicolumn{5}{|l|}{ Operator (2 vs. others) } \\
\hline 2 vs. 1 & -0.158 & -3.891 & 3.575 & 0.932 \\
\hline Others vs. 1 & 4.542 & 0.281 & 8.801 & 0.037 \\
\hline Previous surgery (Yes vs. No) & -0.224 & -3.486 & 3.036 & 0.890 \\
\hline \multicolumn{5}{|l|}{ ASA } \\
\hline |l vs. I & -1.182 & -4.752 & 2.387 & 0.507 \\
\hline III vs. I & 1.827 & -2.743 & 6.397 & 0.423 \\
\hline \multicolumn{5}{|l|}{ BMI } \\
\hline 2 vs. 1 & -2.395 & -5.981 & 1.191 & 0.184 \\
\hline 3 vs. 1 & -2.484 & -7.206 & 2.236 & 0.293 \\
\hline Hernia duration ( $\geq 96$ weeks vs. $<96$ weeks) & -2.186 & -5.371 & 0.998 & 0.173 \\
\hline \multicolumn{5}{|l|}{ Multifactor } \\
\hline Constant term & 13.876 & 9.532 & 18.220 & $<0.0001$ \\
\hline Bilateral & -4.032 & -7.48125 & -0.58391 & 0.023 \\
\hline ASA (I, II vs. III) & -3.556 & -6.727145 & -0.3855 & 0.029 \\
\hline Date of procedure & -1.345 & -2.142 & -0.547 & 0.002 \\
\hline
\end{tabular}

month. After the $6^{\text {th }}$ month 7 patients started to suf- 2 or 3 , and after the $6^{\text {th }}$ month it was $70 \%$ lower for fer ailments although they had not suffered them patients with $\vee$ type mesh, these results are not stabefore. The consistency of the results was $61 \%$. tistically significant (Table IX). None of the variables Although the risk of ailments after the $3^{\text {rd }}$ month analysed (including pain and ailments) influenced increased 3 times for patients with BMI equalled considerably the level of life quality after the $3^{\text {rd }}$ and 
Table VIII. Poisson regression model for pain occurring: up to 3 months and up to 6 months

\begin{tabular}{|lcccc|}
\hline Variable & IRR & \multicolumn{2}{c|}{$95 \%$ Cl (IRR) } & Value of $p$ \\
\hline Up to 3 months & & & & 0.034 \\
\hline Operator (others vs. 1,2) & 10.534 & 1.190 & 93.221 & 0.059 \\
\hline ASA (III vs. other) & 4.907 & 0.943 & 25.540 & 0.092 \\
\hline Up to 6 months & & & & 0.044 \\
\hline Operator (others vs. 1,2) & 3.976 & 0.796 & 19.849 & 79.474 \\
\hline Type of hernia 2 vs. other & 9.193 & 1.063 & & 0.049 \\
\hline
\end{tabular}

Table IX. Results for logistic regression model for ailments up to 3 months and up to 6 months

\begin{tabular}{|llccc|}
\hline Variable & OR & \multicolumn{2}{c}{$95 \% \mathrm{Cl}$ (OR) } & Value of $p$ \\
\hline BMI (2,3 vs. 1) up to 3 months & 2.946 & 0.820 & 10.580 & 0.098 \\
\hline Type of mesh (V vs. P) up to 6 months & 0.307 & 0.077 & 1.219 & 0.093 \\
\hline
\end{tabular}

Table X. Circumstances in which ailments occurred after $3^{\text {rd }}$ and $6^{\text {th }}$ months after the procedure

\begin{tabular}{|lcc|}
\hline Circumstances & $\begin{array}{c}\text { After } 3 \text { months } \\
n(\%)^{*}\end{array}$ & $\begin{array}{c}\text { After } 6 \text { months } \\
n(\%)^{*}\end{array}$ \\
\hline At work, after meal & $5(12)$ & $10(24)$ \\
\hline After/when walking & $4(10)$ & $3(7)$ \\
\hline When coughing & $1(2)$ & 0 \\
\hline $\begin{array}{l}\text { When changing body } \\
\text { position }\end{array}$ & $4(10)$ & $1(2)$ \\
\hline When driving/riding a bike & $2(5)$ & 0 \\
\hline In sitting/tuck position & $6(14)$ & $3(7)$ \\
\hline No regard to the activity & $2(5)$ & $2(5)$ \\
\hline
\end{tabular}

*Percentage does not sum up to 1 due to more than 1 circumstance in case of 1 person

$6^{\text {th }}$ month. Circumstances which accompanied ailments impeding everyday activities are presented in Table X.

The assessment of the surgical and plastic results on the $7^{\text {th }}$ day, after the $3^{\text {rd }}$ and $6^{\text {th }}$ month following the surgery.

In all the patients proper wound healing was observed on the $7^{\text {th }}$ day after the procedure and the plastic condition was assessed as good. After the $3^{\text {rd }}$ month, 4 cases of scar healing were assessed as bad (keloid), including 35 with P mesh (12.5\%) and 1 with $\checkmark$ mesh (6\%).
All the cases were assessed by a doctor as producing bad plastic results. Additionally, 1 case of proper wound healing with a bad plastic result was observed for $\mathrm{P}$ mesh. On the $7^{\text {th }}$ day, 33 patients out of $41(80 \%)$ subjectively assessed the results of surgery as very good, 7 as good (17\%) and 1 as acceptable (2\%). At the same time, plastic results were assessed as very good by 26 patients (63\%), as good by 14 patients (34\%) and as acceptable by 1 patient (2\%). None of the variables analysed had a significant influence on the surgical and plastic results on the $7^{\text {th }}$ day. After the $3^{\text {rd }}$ month 37 patients (90\%) assessed the surgical results as very good, $3(7 \%)$ as good and 1 as bad (2\%). At the same time, plastic results were assessed as very good by 32 patients (78\%), as good by 8 patients (19\%) and by 1 patients as acceptable (2\%). After the $3^{\text {rd }}$ month 37 patients $(90 \%)$ assessed the surgical results as very good, $2(5 \%)$ as good and 1 as bad (2\%). At the same time, plastic results were assessed as very good by 35 patients (85\%), as good by 5 patients (12\%) and by 1 patient as acceptable (2\%). None of the variables analysed (also ailments after the $3^{\text {rd }}$ and $6^{\text {th }}$ month) had a significant influence on the patient's or doctor's subjective assessment of the surgical and plastic results.

\section{Discussion}

The aim of the study was to assess the treatment results and answer the question whether, in fact, par- 
tially absorbable lightweight mesh Vypro II (V) in comparison to non-absorbable, heavyweight mesh $(P)$ in the case of Lichtenstein open inguinal hernia repair confers expected benefits such as diminished pain, decreased percentage of ailments connected with the presence of a foreign body, faster return to activities of daily living and influence of mesh type on the risk of recurrence. Studies prove that the amount and structure of the material have a substantial impact on the scar formation and intensity of chronic, inflammatory reaction to the presence of a foreign body. Heavyweight polypropylene, tightly braided meshes cause more intense inflammatory reaction and keloid formation in comparison to lightweight polypropylene or partially absorbable meshes $[13,14,20]$. That is why the improvement of treatment results was expected when light meshes causing a decreased inflammatory reaction were employed. The suggested superiority of lightweight meshes was confirmed in clinical trials with various, including short, observation periods $[11,13,14]$. However, results of subsequent studies are not so convincing and do not show crucial differences with different type of meshes $[15,21]$. In the present study, during the 6-month observation period two cases of hernia recurrence were observed (3.4\%), 1 in each group, $\mathrm{P}(2.9 \%)$ and $\mathrm{V}(4 \%)$. The difference between groups is not statistically significant. No increased risk of hernia recurrence was observed after surgery with light, partially absorbable meshes, which was reported by O'Dwyer's et al. and Conze et al. [14, 22]. The authors look for causes of increased hernia recurrence in faulty surgical technique rather than in the flaw of the material itself. Such a conclusion is also supported by the results of Polish and other studies [3, 9], which did not confirm a negative influence of lightweight meshes on the percentage of hernia recurrence. The risk of recurrence was comparable for different types of meshes [15-17]. The total percentage of hernia recurrence observed by us in both groups (3.4\%) is higher or comparable with the results of other authors, who observed the percentage from $2 \%$ to $8 \%[23,24]$. However, it is much higher than the small percentage (below 1\%) of hernia recurrence which appears in the centres specializing in hernia repair $[2,25]$. The majority of randomized clinical studies comparing the results of inguinal hernia repairs with different meshes have concentrated on assessment of the influence of the mesh employed on the hernia recurrence rate, cases of chronic pain and time of postoperative recovery. Our study, apart from the above-mentioned factors, included assessment of the influence of hernia type and duration, previous hernia strangulation, BMI, general health condition (ASA), type of professional activity, and the surgeon performing the procedure on the length of the procedure, the occurrence of intraoperative anatomical damage, early complications, the length of hospital stay, analgesic requirements, postoperative pain intensity assessed in various intervals and ailments such as sensations connected with presence of a foreign body. No statistically significant influence of the mesh and hernia type on the risk of early complications in 9 cases (16\%) was observed. It can be concluded from data available in the literature that the general risk of postoperative inguinal hernia repair complications is estimated at $15-28 \%[26,27]$, and early complications, which most often include hematoma and serum tumour, at 8-22\% [26-28]. A statistically significant influence of increased occurrence rate of early complications probability was observed for hernia strangulation in the patient's medical history (over 6-fold increase), and obesity or overweight, which increased the probability of complications 5 times in comparison to patients with the proper body mass. Similar observations connected to body mass were made by other authors $[29,30]$. Our study showed that when the partially absorbable mesh was used, the length of the procedure was significantly reduced by $7.5 \mathrm{~min}$ in patients with the same operative risk (ASA) if the procedure had been performed by the same surgeon in the given, 2-month interval of the trial. The significantly shorter length of the procedure with the partially absorbable mesh observed in the study may mean easier implementation. The results of similar studies are varied. In some, the authors observe no significant difference in the length of the procedure in relation to the mesh type [24]. Others show that procedures with a non-absorbable mesh are shorter, which suggests that its implementation is easier [21]. The prolongation of time of surgery by 7 min in the case of hernia duration of more than 96 weeks is obvious and connected with the dissection of the substantially bigger hernia. No significant influence of mesh and hernia type on the length of postoperative hospital stay was observed, which is confirmed by other reports $[17,18]$. The length of hospital stay depended on concurrent diseases determining the patients' clinical condition. Increased 
analgesic requirement was observed in the case of partially absorbable mesh in comparison to nonabsorbable mesh, and patients with hernia type 2 required smaller doses of painkillers in comparison to patients with other hernia types. The analysed interactions between the mesh and hernia type revealed that partially absorbable mesh used in patients with hernia type 3 and 4 caused decreased analgesic requirement in comparison to patients with hernia type 1 and 2 and the same type of mesh employed. The analyses of changes in time of the analgesic needed showed that only patients with hernia type 1 differ from the others significantly. When nonabsorbable mesh was used they used the smallest amounts of ketoprophen and when partially absorbable mesh was employed they used the biggest amount of analgesic in comparison to the other patients. The authors do not have at their disposal other results proving the influence of the mesh type. These findings need confirmation in a larger series of patients. Our study did not show a significant influence of the mesh and hernia type on the recovery time, although some reports demonstrate the substantial supremacy of partially absorbable meshes [17, 21]. The use of lightweight meshes, according to the majority of reports, was connected with lower pain intensity in both the immediate and long-term postoperative period [13, 14, 16]. Our study did not reveal any significant influence of the mesh and hernia type on occurrence and intensity of postoperative pain. High individual differentiation of pain levels among patients and general decrease of pain intensity over time, 0.13 per day on average, were observed. These observations suggest that pain occurrence and intensity are mostly associated with the damage itself rather than with the presence of mesh. No significant influence of the mesh type on chronic pain occurrence, lasting more than 3 months following the surgery, was proven. The occurrence of chronic pain after inguinal hernia repair is estimated at $10-30 \%$ of those operated on $[10,12,30]$, and the comparison and interpretation of the results is hindered by different definitions of chronic pain (from 1 months to 6 months) used in publications [31]. Although in our study the risk of ailments such as foreign body presence and prickly or pinching sensations determined after the $6^{\text {th }}$ month were $70 \%$ lower in patients with partially absorbable mesh, the result appeared to be statistically insignificant. However, the advantage of lightweight meshes is con- firmed by the results of similar trials [13-15]. No ailments occurring after the $3^{\text {rd }}$ and $6^{\text {th }}$ month which hampered a patient's ability to perform everyday tasks were observed. What is more, patients with proper body mass were determined to be at 3 times lower risk of ailments of such type in comparison with obese or overweight patients. The subjective assessment of the vast majority of plastic and surgical results (resolution of ailments caused by hernia) made on the $7^{\text {th }}$ day after the $3^{\text {rd }}$ and $6^{\text {th }}$ month was positive. Ailments, occurring in some cases, did not significantly influence the patient's and doctor's subjective assessment of surgical and cosmetic results made in the $3^{\text {rd }}$ and $6^{\text {th }}$ month. It confirms the positive opinion of Lichtenstein technique prevailing among patients and doctors. Benefits achieved by the resolution of ailments caused by hernia are substantial enough to conceal chronic, less pronounced ailments which as a result do not hamper everyday activities or diminish quality of life [6, 11, 16, 21, 31]. The assessed method learning curve and the technical skill having become more advanced resulted in shorter duration of the procedure, diminished risk of immediate complications and improved results as patients returned to everyday activities earlier. This relationship is confirmed by other reports [3, 25] assessing the technical skill of the operator. Significant differences in surgical parameters observed such as the procedure duration, the amount of drainage, the length of hospital stay, and analgesic requirement show that procedures were performed by surgeons at different levels of training and skill which determined the extent of surgical damage. The evident influence of the operator on preliminary results of treatment, observed during the first few postoperative days, appeared to be insignificant in the case of results assessed after the $3^{\text {rd }}$ and $6^{\text {th }}$ month following the surgery. Other reports confirm these observations, where long-term results of surgery performed by both expert and learning surgeons are comparable and highly assessed by patients and doctors, who believe that the Lichtenstein technique is an optimal method for inguinal hernia repair $[2,3,6]$.

\section{Conclusions}

The early results of the trial presented above confirm that the Lichtenstein method is equally successful in preventing hernia recurrence with both types of 
meshes. The type of mesh does not have any significant influence on the intraoperative damage, risk of immediate complications, amount of drainage, postoperative pain intensity assessed on the VAS scale, subjective assessment of treatment effectiveness (resolution of ailments caused by hernia) or on the assessment of plastic results made by a patient and a doctor. It appears that lightweight mesh decreases the risk of ailments after the $6^{\text {th }}$ month when compared with heavyweight, non-absorbable mesh. Easier implementation of partially absorbable $(\mathrm{V})$ mesh was confirmed by shorter duration of the procedure. Vypro II (V) increased the amount of analgesics used in comparison to polypropylene mesh. What is more, a statistically significant influence of the surgeon (their accuracy and expertise) on the length of the procedure, the amount of drainage, the length of hospital stay and recovery was observed. The immediate results of the study require confirmation in a larger series of patients.

\section{References}

1. Simons MP, Aufenacker T, Bay-Nielsen M, et al. European Hernia Society guidelines on the treatment of inguinal hernia in adult patients. Hernia 2009; 13: 343-403.

2. Amid PK. Lichtenstein tension-free hernia repair: its background and evolution with focus on avoiding postherniorrhaphy chronic pain. Videosurgery and Other Miniinvasive Techniques 2009; 4: 26-31.

3. Mitura K, Romańczuk M. Redundant modifications of Lichtenstein technique in hernia repair - a descriptive study of practising surgeons in Poland. Videosurgery and Other Miniinvasive Techniques 2009; 4: 1-5.

4. Czudek S, Skrovina M, Adamcik L. Laparoscopic treatment of inguinal hernia - TOM (transabdominal onlay mesh). Videosurgery and Other Miniinvasive Techniques 2009; 4: 16-9.

5. Kirschniak A, Shiozawa T, Küper M, et al. Transumbilical singleincision laparoscopic inguinal hernia repair - feasibility study on anatomical specimens. Videosurgery and Other Miniinvasive Techniques 2010; 5: 72-5

6. Matyja A, Kibil W, Pach R, et al. Assessment of inguinal hernia treatment results in patients operated on with mesh using Lichtenstein, PHS and Robbins-Rutkow techniques. Videosurgery and Other Miniinvasive Techniques 2010; 5: 27-34.

7. EU Hernia Trialists Collaboration. Repair of groin hernia with synthetic mesh: meta-analysis of randomized controlled trials. Ann Surg 2002; 235: 322-32.

8. Morales-Conde S. Sportsman's hernia: an entity to be defined, diagnosed and treated properly? Videosurgery and Other Miniinvasive Techniques 2009; 4: 32-41.

9. Polish Hernia Study Group. Influence of operative technique on recurrence rate in Lichtenstein hernioplasty using partially absorbable „lightweight”weight mesh. Videosurgery and Other Miniinvasive Techniques 2009; 4: 10-5.
10. Nienhuijs S, Staal E, Strobbe L, et al. Chronic pain after mesh repair of inguinal hernia: a systematic review. Am J Surg 2007; 194: 394-400.

11. Paradowski T, Olejarz A, Kontny T, et al. Polypropylene vs. ePTFE vs. WN mesh for Lichtenstein inguinal hernia repair - a prospective, randomized, double blind pilot study of one-year follow-up. Videosurgery and Other Miniinvasive Techniques 2009; 4: 6-9.

12. Erhan Y, Erhan E, Aydede H, et al. Chronic pain after Lichtenstein and preperitoneal (posterior) hernia repair. Can J Surg 2008; 51 : 383-7.

13. Post S, Weiss B, Willer M, et al. Randomized clinical trial of ,lightweight" weight composite mesh for Lichtenstein inguinal hernia repair. Br J Surg 2004; 1: 44-8.

14. O'Dwyer PJ, Kingsnorth AN, Molloy RG, et al. Randomized clinical trial assessing impact of a ,lightweight”weight or „,heavyweight"weight mesh on chronic pain after inguinal hernia repair. Br J Surg 2005; 92: 166-70.

15. Bringman S, Wollert S, Osterberg J, et al. Three-year results of a randomized clinical trial of „lightweight”weight or standard polypropylene mesh in Lichtenstein repair of primary inguinal hernia. Br J Surg 2006; 93: 1056-9.

16. Śmietański M; Polish Hernia Study Group. Randomized clinical trial comparing a polypropylene with a poliglecaprone and polypropylene composite mesh for inguinal hernioplasty. $\mathrm{Br}$ J Surg 2008; 95: 1462-8.

17. Koch A, Bringman S, Myrelid P, et al. Randomized clinical trial of groin hernia repair with titanium-coated „lightweight”weight mesh compared with standard polypropylene mesh. Br J Surg 2008; 95: 1226-31.

18. Paajanen $\mathrm{H}$. A single-surgeon randomized trial comparing three composite meshes on chronic pain after Lichtenstein hernia repair in local anesthesia. Hernia 2007; 11: 335-9.

19. Zollinger RM. An updated traditional classification of inguinal hernias. Hernia 2004; 8: 318-22.

20. Junge $K$, Klinge $U$, Rosch $R$, et al. Functional and morphologic properties of a modified mesh for inguinal hernia repair. World J Surg 2002; 26: 1472-80.

21. Bringman S, Heikkinen TJ, Wollert S, et al. Early results of a single-blinded, randomized, controlled, Internet-based multicenter trial comparing Prolene and Vypro II mesh in Lichtenstein hernioplasty. Hernia 2004; 8: 127-34.

22. Conze J, Kingsnorth AN, Flament JB, et al. Randomized clinical trial comparing ,lightweight”weight composite mesh with polyester or polypropylene mesh for incisional hernia repair. Br J Surg 2005; 92: 1488-93.

23. Douek M, Smith G, Oshowo A, et al. Prospective randomised controlled trial of laparoscopic versus open inguinal hernia mesh repair: five year follow up. BMJ 2003; 326: 1012-3.

24. Miedema BW, Ibrahim SM, Davis BD, et al. A prospective trial of primary inguinal hernia repair by surgical trainees. Hernia 2004; 8: 28-32.

25. Śmietański M, Bigda J; Polish Hernia Study Group. The influence of carrying out multicentre trials on surgical practice in general surgery departments. Videosurgery and Other Miniinvasive Techniques 2009; 4: 20-5.

26. Bittner R, Sauerland S, Schmedt CG. Comparison of endoscopic techniques vs Shouldice and other open nonmesh techniques 
for inguinal hernia repair: a meta-analysis of randomized controlled trials. Surg Endosc 2005; 19: 605-15.

27. Schmedt CG, Sauerland S, Bittner R. Comparison of endoscopic procedures vs Lichtenstein and other open mesh techniques for inguinal hernia repair: a meta-analysis of randomized controlled trials. Surg Endosc 2005; 19: 188-99.

28. Mc Cormack K, Scott NW, Go PM, et al; EU Hernia Trialists Collaboration. Laparoscopic techniques versus open techniques for inguinal hernia repair. Cochrane Database Syst Rev 2003; 1 : CD001785.

29. Lindström D, Sadr Azodi O, Bellocco R, et al. The effect of tobacco consumption and body mass index on complications and hospital stay after inguinal hernia surgery. Hernia 2007; 11: $117-23$.

30. Osemek P, Paśnik K, Trojanowski P. Huge, irreducible femoral hernia interpreted as a preperitoneal lipoma in radiological findings. Videosurgery and Other Miniinvasive Techniques 2010; 5: 35-7.

31. Nikkolo C, Lepner U, Murruste M, et al. Randomised clinical trial comparing ,lightweight”weight mesh with „heavyweight” weight mesh for inguinal hernioplasty. Hernia 2010; 14: 253-8. 